\title{
ARTIGOS
}

Recebido em 17.04.2012. Aprovado em 17.08.2012

Avaliado pelo sistema double blind review. Editor Científico: Luiz Carlos Murakami

\section{NOSTALGIA, ANTICONSUMO SIMBÓLICO E BEM-ESTAR: A AGRICULTURA URBANA}

\author{
Nostalgia, symbolic anticonsumption and well-being: urban agriculture \\ Nostalgia, anticonsumo simbólico y bienestar: la agricultura urbana
}

BRUNO HENRIQUE COMASSETTO brunocomassetto@yahoo.com.br Mestrando em Administração de Empresas pelo Programa de Pósgraduação em Administração, Universidade Federal do Rio Grande do Sul - Porto Alegre - RS, Brasil

\section{GABRIELA P. SOLALINDE $Z$.}

gabysolalinde@hotmail.com Mestranda em Administração de Empresas pelo Programa de Pósgraduação em Administração, Universidade Federal do Rio Grande do Sul - Porto Alegre - RS, Brasil

\section{JOÃO VICENTE ROSA DE SOUZA}

\section{joaovsouza@gmail.com}

Mestrando em Administração de Empresas pelo Programa de Pósgraduação em Administração, Universidade Federal do Rio Grande do Sul - Porto Alegre - RS, Brasil

\section{MARCELO TREVISAN}

marcelotrev@gmail.com

Doutorando em Administração de Empresas pelo Programa de Pós-graduação em Administração, Universidade Federal do Rio Grande do Sul - Porto Alegre - RS, Brasil

\section{PAULO RICARDO ZILIO ABDALA}

pauloabdala@hotmail.com Doutorando em Administração de Empresas pelo Programa de Pós-graduação em Administração, Universidade Federal do Rio Grande do Sul - Porto Alegre - RS, Brasil

\section{CARLOS ALBERTO VARGAS ROSSI} cavrossi@ea.ufrgs.br Professor do Programa de Pósgraduação em Administração, Universidade Federal do Rio Grande do Sul - Porto Alegre - RS, Brasil

\section{RESUMO}

O estabelecimento de uma cultura de consumo, disseminada globalmente nos últimos anos, teve como consequência a crescente preocupação das pessoas com o impacto dos níveis de consumo sobre o ambiente e seu bem-estar pessoal. Nesse contexto, surge a Agricultura Urbana (AU) associada a diversos benefícios ambientais, sociais e relativos à saúde (SLATER, 2001). 0 propósito do estudo foi compreender o significado da AU como fenômeno de consumo, identificando as distintas teorias que estão vinculadas a ela, bem como suas inter-relações. Desenvolveu-se uma pesquisa qualitativa com entrevistas em profundidade. Os entrevistados são especialistas em agricultura urbana e praticantes da atividade, residentes em nove bairros da área urbana de uma grande capital brasileira. Com base nos resultados, percebe-se dupla motivação para a prática da AU: uma extrínseca (o exemplo) e outra intrínseca (o bem-estar). Há vinculação da prática da AU com (a) a preocupação com o meio ambiente, a saúde e o bem-estar próprio e dos demais e (b) com o respeito e orgulho nostálgico por uma herança cultural.

PALAVRAS-CHAVE | Agricultura urbana, anticonsumo simbólico, bem-estar, nostalgia, flow.

\begin{abstract}
The establishment of a global consumption culture had as a consequence a growing concern with the impact of consumption practices on the environment, as well as on the general and personal well -being. In this context emerges the urban agriculture (UA) associated to environmental, social and health benefits (SLATER, 2001). The objective of this study is to understand the meaning of the UA phenomenon as a consumption practice, identifying which theories are related to it. In order to reach that goal, a qualitative research used as data collection in-depth interviews. The subjects were experts and practitioners in UA living in 9 neighborhoods in urban areas of a Brazilian city with a population bigger than 1 million inhabitants. Results showed double motivation for the UA practice, extrinsic (example) and intrinsic (well-being), linking the UA to environmental concerns, to health and well-being, and the respect and pride for a nostalgic cultural heritage.
\end{abstract}

KEYWORDS I Urban agriculture, simbolic anticonsumption, well-being, nostalgia, flow.

\section{RESUMEN}

El establecimiento de una cultura de consumo, diseminada globalmente los últimos años, tuvo como consecuencia la creciente preocupación de las personas con e impacto de los niveles de consumo sobre el entorno y su bienestar personal. En ese contexto, surge la Agricultura Urbana (AU) asociada a diversos beneficios ambientales, sociales y relativos a la salud (SLATER, 2001). El propósito del estudio fue comprender el significado de la AU como fenómeno de consumo, identificando las diferentes teorías que están vinculadas a ella, así como sus interrelaciones. Se desarrolló un estudio cualitativo con entrevistas en profundidad. Los entrevistados son especialistas en agricultura urbana y practicantes de la actividad, residentes en nueve barrios del área urbana de una gran capital brasileña. Con base en los resultados, se percibe una doble motivación para la práctica de la AU: una extrínseca (el ejemplo) y otra intrínseca (el bienestar). Hay vínculo de la práctica de la AU con (a) la preocupación con el medio ambiente, la salud y el bienestar propio y de los demás y (b) con el respeto y orgullo nostálgico por una herencia cultural.

PALABRAS CLAVE I Agricultura urbana, anticonsumo simbólico, bienestar, nostalgia, flow. 


\section{INTRODUÇÃO}

A origem e a qualidade dos alimentos, aliadas à preservação da natureza e ao desejo de sentir-se com saúde e bem-estar, recebem atenção crescente das pessoas, especialmente daquelas que residem em áreas de considerável densidade demográfica e que adotam um intenso ritmo de vida. Nesse contexto, surge o conceito de agricultura urbana (AU) no que se refere ao cultivo de vegetais nas cidades e à criação de pequenos animais em quintais, às margens de ruas e sacadas (SMIT E NASR, 1992). A AU "significa atividades de agricultura e jardinagem (como produção de vegetais, criação de animais, hidroponia, flores e jardins ornamentais) em áreas tanto urbanas como periurbanas" (Slater, 2001, p. 635).

Diversos benefícios ambientais, sociais e relativos à saúde são apontados pelos que advogam em favor da prática da AU. Primeiro, cultivar o alimento perto do local de consumo diminui a quantidade de combustível necessária para sua distribuição e cultivo (DESPOMMIER, 2009). Outro ponto importante é que muitos que realizam essa atividade utilizam métodos ecológicos, buscando fechar o ciclo de nutrientes, como o uso de resíduos orgânicos, que permitem significativos ganhos ambientais. Além disso, o trabalho como o do agricultor reintegra o ser humano na natureza, colocando-o em contato com o ambiente físico (solo, plantas, água, insetos, pássaros), retornando parcialmente os meios de produção e o resultado direto do trabalho para o indivíduo (MCCLINTOCK, 2010), o que modifica seu papel de consumidor.

Sendo assim, o objetivo desta pesquisa foi compreender o significado da experiência de agricultura urbana como um fenômeno de consumo. Este estudo se insere no contexto da busca por práticas alternativas de consumo, propiciando uma reflexão sobre as complexas relações entre bem-estar, sustentabilidade e consumo na sociedade contemporânea, uma das preocupações das teorias de anticonsumo. Os resultados são importantes para que os gestores compreendam as demandas de um número crescente de consumidores preocupados com o bem-estar e com o significado daquilo que consomem.

Para atingir o objetivo mencionado, desenvolveu-se uma pesquisa de natureza interpretativa e fenomenológica, tendo entrevistas em profundidade como seu método principal de coleta de dados. Segundo os pressupostos dessa abordagem, a pesquisa parte dos sujeitos e a compreensão da realidade vivida por eles é uma forma de contribuir com o desenvolvimento teórico (THOMPSON, 1997). Tal perspectiva possibilitou a emergência no campo do conceito de anticonsumo simbólico, uma forma simbólica de resistência às práticas mainstream de mercado, sendo o argumento de pesquisa e o quadro referencial construídos em diálogo com o ponto de vista dos participantes da investigação, especialistas em AU e praticantes da atividade residentes em bairros da área urbana de uma capital brasileira.

0 artigo tem como argumento central a ideia de que a $\mathrm{AU}$ é uma forma de consumo simbólico que questiona a lógica contemporânea de mercado. Isto é, remete a relações nostálgicas de consumo e produção enquanto resgate da herança cultural, proporcionando uma sensação de bem-estar intrínseco, bem como de flow e prazer, servindo de exemplo social. É uma espécie de ponte viva para as tradições do passado.

0 trabalho está estruturado em quatro partes, além desta introdução. A primeira aborda elementos que visam fundamentá-lo: anticonsumo, consumo simbólico, nostalgia, bem-estar subjetivo e flow. A segunda refere-se ao método. A terceira apresenta a análise dos resultados e, em seu término, são evidenciadas as considerações finais.

\section{ANTICONSUMO}

O estabelecimento de uma cultura de consumo tem sido acompanhado pela preocupação crescente de indivíduos com seu impacto sobre o ambiente natural, bem como sobre o próprio bem-estar e dos outros (DIAMANTOPOULOS e outros, 2003). Movimentos de antiglobalização com mensagens anticonsumo assumiram um lugar central na política, oferecendo oposição à corrente de consumismo capitalista (GABRIEL e LANG, 2008).

Thompson e Coskuner-Bali (2007) analisam o caso de uma comunidade que suporta a agricultura local enfatizando os riscos ecológicos, que resultam da agricultura intensiva, e a quantidade de energia não renovável utilizada para transportar os produtos, além de mencionarem prejuízo econômico sofrido pelas fazendas locais. Ademais, o sentimento antiglobalização mistura-se com idealizações românticas, uma vez que as comunidades rurais funcionam como guias morais de virtudes e os agricultores são vistos como nobres artesãos responsáveis por custodiar a terra.

Analogamente, há o estudo de Sassatelli e Davolio (2010) sobre a organização Slow Food, cujas metas são, além de defender a boa comida, o prazer gastronômico e os métodos de cultivo e conservação, proteger a biodiversidade de variedades silvestres e cultivadas.

Outro caso mais extremo do comportamento dos consumidores, no qual questões sociais e éticas influenciam as decisões de compra, são os boicotes, vistos por Klein, Smith e John (2004) como atos coletivos em que o benefício individual se vê limitado em favor do bem social. Isso é consistente com o trabaIho de Shaw, Newholm e Dikinson (2006), o qual explora o poder 
dos consumidores por meio de atos de punição, como manifestações e boicotes às empresas que reportam práticas questionáveis, e, por outro lado, estimula a habilidade de recompensar aqueles que se comportam eticamente no ato da compra.

Hogg, Banister e Stenphenson (2009), referindo-se ao anticonsumo e ao consumo simbólico, explicam que as pessoas utilizam o consumo como maneira de pertencer a um grupo. A seguir são apresentados detalhes do consumo simbólico, importante elemento desta investigação.

\section{CONSUMO SIMBÓLICO}

As pessoas compram produtos por sua utilidade e também pelo que representam (LEVY, 1959). Algumas vezes, as características funcionais dos produtos constituem a razão principal que motiva a compra; em outras, a compra pode estar relacionada ao símbolo que o produto transmite (YOO, CHUNG e HAN, 2006). Os produtos têm essa capacidade devido ao significado simbólico inerente a eles (BELK, 1988).

Símbolo é um termo geral utilizado quando a experiência é mediada, em vez de ser direta, fazendo com que um objeto, palavra, imagem ou comportamento complexo signifique não somente ele mesmo, mas também outras ideias ou sentimentos (LEVY, 1959). A utilização de produtos como símbolo capaz de estabelecer comunicação de uma pessoa com as demais está vinculada a seu uso para o desenvolvimento da identidade pessoal (PIACENTINI e MAILER, 2004). Assim, os produtos que um indivíduo compra, as atividades que realiza e as filosofias e crenças que segue dizem respeito a quem ele é e com o que se identifica (WATTANASUWAN, 2005), atuando como sinais ou informações transmitidas para si e para os outros (ELLIOTT, 1997).

Investigando como o animal de estimação pode estar conectado à construção da identidade do proprietário (consumidor), Jyrinki (2012) identificou que os donos desses bichos os relacionam como extensões de si mesmos. A autora encontrou outras relações sobre como a posse do animal contribui para construir a identidade de quem o possui. Algumas são: fonte de bem-estar, meios de contato, comunicação de status e objeto de devoção, inseridas nas interações sociais dos proprietários. Segundo Yoo, Chung e Han (2006), o significado social que o produto transmite, como status e imagem na sociedade, pode representar o motivo principal de sua compra.

Além do valor funcional e simbólico do produto, Baudrillard (2008) afirma que o processo de consumo pode ser analisado sob dois aspectos fundamentais. Primeiro, como processo de significação e de comunicação, de modo que o consumo se revela como um sistema de permuta equivalente a uma lin- guagem. Segundo, como processo de classificação e de diferenciação social, em que os objetos/signos se ordenam, não só como diferenças significativas no interior de um código, mas também como valores estatutários no seio de uma hierarquia. Entretanto, a pessoa não possui total autonomia quanto à sua identidade, pois está sujeita às relações que estabelece com as demais (JYRINKI, 2012), como as relações nostálgicas com a tradição e o passado.

\section{NOSTALGIA}

A área de marketing tem se interessado pelas maneiras que a nostalgia influencia o comportamento do consumidor. Nostalgia é definida como uma:

preferência (gosto geral, atitude positiva ou efeito favorável) com relação a objetos (pessoas, lugares ou coisas) que eram mais comuns (populares, da moda, ou mais presentes) quando se era mais jovem (na juventude, adolescência, na infância ou até mesmo antes do nascimento). (HOLBROOK e SCHINDLER, 2003, p. 108)

Holbrook trabalhou no desenvolvimento de uma escala para mensurar o gosto pelo passado e pelo presente, fazendo uma relação entre ambas as dimensões para verificar o quanto uma pessoa é efetivamente nostálgica (HOLBROOK, 1993).

Outro estudo realizou uma pesquisa interpretativa de caráter fenomenológico sobre nostalgia (SCHINDLER e HOLBROOK, 2003). Os autores identificaram assuntos com os quais a nostalgia está associada: experiências sensoriais, lar, ritos de passagem, amizade e pessoas amadas, presentes de amor, segurança, fuga, arte e entretenimento, desempenho e competência, e criatividade. Cada objeto nostálgico remete, preferencialmente, a uma dessas categorias, sendo as mais importantes para a atual pesquisa, apresentadas a seguir. As experiências sensoriais são "talvez as mais simples, mais orientadas para si mesmo em um nível hedônico", sendo que muitos informantes associaram objetos importantes a experiências de prazer da sua juventude (SCHINDLER e HOLBROOK, 2003, p. 277). O lar relaciona-se com objetos de um local ou época distante, próximo da infância, sendo uma conexão emocional com o aspecto familiar. Já os objetos de fuga lembram momentos de liberdade física, como viajar, enquanto a arte e o entretenimento representam abstração, sair da rotina, uma forma de liberdade espiritual.

Para Goulding (2001, p. 585), a nostalgia pode servir como forma de aliviar a frustração com o presente, pois "essencialmente, aqueles indivíduos que estão felizes, cheios de si e 
em controle, com sólidos sistemas de suporte social, tendem a não reagir nostalgicamente às imagens do passado".

O sentimento nostálgico raramente evoca a realidade sobre o que passou, já que há uma tendência de melhorar o que de fato ocorreu (HOLBROOK, 1993). Isso não significa dizer que a nostalgia é um escapismo patológico do presente, mas pode representar uma estratégia que as pessoas utilizam para lidar com as contradições da vida contemporânea (LYON e COLQUHOUN, 1999).

\section{BEM-ESTAR}

As pessoas reagem diferentemente a uma mesma circunstância, avaliando situações fundamentadas em expectativas, valores e experiências únicas. Por isso, o elemento subjetivo é essencial para determinar a qualidade de vida (DIENER e outros, 1999).

O bem-estar subjetivo é uma avaliação individual tanto cognitiva (satisfação com a vida) quanto afetiva (presença de emoções positivas/prazerosas e ausência de emoções negativas/desagradáveis) (BISWAS-DIENER e DIENER, 2006). Dessa forma, Diener e outros (1999, p. 277) afirmam que "bem-estar subjetivo é uma categoria ampla de fenômenos, incluindo as repostas emocionais da pessoa, satisfações com os domínios de vida e julgamentos globais de satisfação com a vida". A satisfação refere-se ao julgamento do grau de qualidade de vida do indivíduo, o quanto gosta e aprova a existência que leva (VEENHOVEN, 1991).

Estudos mostram que traços de personalidade, em parte, definem o bem-estar, assim como fatores cognitivos e aspectos objetivos - embora as pessoas se adaptem a eles (DIENER e outros, 1999). A felicidade do indivíduo depende, entre outras coisas, de características individuais (como otimismo e autoestima), aspectos econômicos, idade e nível de instrução. Além disso, relacionamentos sociais positivos e saúde são críticos para o bem-estar, embora existam dados que afirmem que se sentir bem com a vida também influencia a formação de bons relacionamentos e a longevidade, ou seja, seria um caminho de duas mãos (DIENER e SELIGMAN, 2004).

Outra linha de pesquisa defende que os afazeres cotidianos influenciam o bem-estar (ETTEMA e outros, 2010). As atividades podem ser motivadas intrinsecamente ou extrinsecamente. Indivíduos motivados especialmente por objetivos extrínsecos, como riqueza e fama, são propensos a ingressar em afazeres que exigem maior controle, tendem a gerar estresse e afetar negativamente sua saúde e bem-estar. Por sua vez, as atividades motivadas intrinsecamente são aquelas que os indivíduos realizam para se sentirem competentes e eficazes, sem preocupação com consequências e recompensas da ação. A manutenção e o interesse em tais atividades dependem de eles se sentirem autônomos e competentes em sua realização. A motivação intrínseca associa-se positivamente ao bem-estar (DECY e RYAN, 2000). Embora, de maneira geral, envolver-se em atividades que reflitam necessidades intrínsecas leve a níveis maiores de bem-estar psicológico do que em extrínsecas, pode haver diferenças individuais, isto é, realizar serviço voluntário, por exemplo, pode ser mais satisfatório para alguns indivíduos dependendo de suas características pessoais (OISHI e outros, 1999). Aspectos que possuem expressiva relação com o próximo tópico: o estado mental de flow.

\section{CONCEITO DE FLOW}

As atividades cotidianas a que as pessoas se dedicam contribuem para a sensação de bem-estar. Assim, o estado mental de flow possui importante papel para que os praticantes de determinada atividade obtenham resultados prazerosos. Conforme Csikszentmihalyi (1997a), o que importa não é a atividade que a pessoa realiza, mas como ocorre. O foco está no processo, não importando a natureza da tarefa. Diversos indivíduos se dedicam a passatempos (atividades sem ganhos financeiros) devido à motivação gerada pela qualidade da experiência proporcionada. A essa ótima experiência, Csikszentmihalyi (1997a) denominou flow, um estado de consciência altamente focado, mas que demanda o dispêndio de pouco esforço.

A experiência de flow tende a ocorrer quando a pessoa, ao executar uma atividade, se depara com objetivos bem definidos que requerem respostas apropriadas. Além disso, pode ser observada considerando-se as habilidades envolvidas na tarefa. Dessa forma, as habilidades estão totalmente direcionadas para superar um desafio a que o indivíduo se propõe. A determinação de objetivos claros proporciona oportunidades de desafio se estiverem acima das habilidades, contudo, num estágio alcançável pela pessoa. Se o desafio estiver muito acima das habilidades, causará ansiedade; se estiver abaixo, não levará à motivação. Ambos não resultam na experiência de flow (JACKSON e CSIKSZENTMIHALYI, 2005a).

Para atingir o estado de flow, o foco da pessoa deve estar no ato que realiza, pois sua consciência e ação estão envolvidas no mesmo objetivo (JACKSON e CSIKSZENTMIHALYI, 2005b). Existem elementos-chave que caracterizam a experiência de flow e permitem avaliar se determinada atividade possui capacidade de proporcionar a quem a realiza o alcance do estado mental em questão. Segundo Csikszentmihalyi (1997a), os elementos são: existência de objetivos claros em cada etapa da tarefa, 
retorno imediato de suas ações, equilíbrio entre habilidades e desafios, junção de ação e consciência, exclusão de distrações da consciência, inexistência de preocupação com falhas, desaparecimento da autoconsciência, distorção da percepção temporal e certeza de a atividade ser um fim em si mesma.

A relação entre a experiência de flow e o bem-estar não ocorre, normalmente, durante a execução da tarefa. Mas, após sua realização, o indivíduo experimenta uma sensação de felicidade, resultando no aumento de seu bem-estar (CSIKSZENTMIHALYI, 1997a).

\section{MÉTODO}

Esta é uma pesquisa de natureza qualitativa e interpretativa, com entrevistas em profundidade com inspiração fenomenológica como método principal de coleta de dados. Este tipo de entrevista constitui um método alternativo para estudar a experiência dos consumidores visando à compreensão de temas complexos cujas respostas não se obtêm de maneira superficial (THOMPSON, LOCANDER e POLLIO, 1989).

Para a fenomenologia, como processo de pesquisa, a fonte de dados válida é o ponto de vista dos sujeitos que vivenciam a experiência em estudo, sendo o processo de seleção de participantes proposital e prescritivo (GOULDING, 2005). A partir dessa característica, optou-se por entrevistar 14 pessoas, 12 consideradas praticantes de AU e duas classificadas como especialistas na área (as últimas possuem pósgraduação em Agronomia, são autores de livros, empresários do setor e ministram cursos sobre essa atividade). 0 número foi considerado suficiente para a compreensão do fenômeno pelos pesquisadores, visto que, na fenomenologia, a "primazia da experiência subjetiva é considerada crucial” (GOULDING, 2005, p. 303).

Os praticantes residem em nove bairros da área urbana de uma capital brasileira, cuja população é de aproximadamente 1,5 milhão de habitantes e tem extensão em torno de 500 $\mathrm{km}^{2}$, obtendo uma densidade demográfica próxima a 2.800 habitantes por km² (IBGE, 2011). Observando-se a Tabela 1, constata-se que a densidade demográfica dos bairros envolvidos neste estudo varia de 3.152,47 a 24.652,63 habitantes por km², cujo rendimento médio dos responsáveis por domicílio está entre 4,40 e 15,80 salários mínimos. Dos sujeitos pesquisados, três são homens e onze mulheres. Conforme evidencia o Quadro 1 , suas idades variam de 31 a 75 anos e o nível de instrução oscila entre pessoas com ensino fundamental e mestrado. Suas atividades profissionais são variadas e residem em casas, apartamentos ou cobertura.

\section{TABELA 1. Densidade demográfica e rendimento médio dos responsáveis por domicílio nos bairros pesquisados}

\begin{tabular}{c|c|c}
\hline Bairro & $\begin{array}{c}\text { Densidade } \\
\text { demográfica } \\
\text { (habitantes/km²) }\end{array}$ & $\begin{array}{c}\text { Rendimento médio dos } \\
\text { responsáveis } \\
\text { por domicílio (salários mínimos) }\end{array}$ \\
\hline 1 & $24.652,63$ & 15,25 \\
\hline 2 & $19.917,20$ & 11,10 \\
\hline 3 & $15.310,04$ & 12,80 \\
\hline 4 & $13.904,44$ & 14,00 \\
\hline 5 & $13.297,40$ & 15,80 \\
\hline 6 & $10.069,13$ & 11,10 \\
\hline 7 & $7.717,26$ & 8,47 \\
\hline 8 & $7.709,18$ & 9,40 \\
\hline 9 & $3.152,47$ & 4,40 \\
\hline
\end{tabular}

Fonte: Observatório da cidade pesquisada, 2011.

Os entrevistados foram contatados por meio do método bola de neve e adotou-se o critério de que os praticantes de AU fossem moradores da área urbana dessa capital. Apenas os dois especialistas residiam em uma cidade da região metropolitana da capital (Quadro 1).

A coleta de dados foi realizada durante os meses de janeiro e fevereiro de 2011, seguindo os princípios da entrevista fenomenológica propostos por Thompson, Locander e Pollio (1989). Um roteiro contendo tópicos foi utilizado para guiar as entrevistas e assegurar que os temas principais fossem cobertos. Os respondentes foram encorajados a descrever suas experiências na prática de AU. Para tanto, as entrevistas foram realizadas nos domicílios dos sujeitos pesquisados por considerá-los um local capaz de propiciar o diálogo aberto, viabilizando o registro de fotografias dos praticantes e de suas plantas, comprovando a atividade de AU. Entre as culturas plantadas, destacam-se diversas espécies de árvores frutíferas, vários tipos de chá e tempero, alface e tomate. As entrevistas foram gravadas e transcritas para posterior interpretação e análise.

0 primeiro passo para a interpretação constituiu-se de uma leitura detalhada de cada uma das transcrições com o intuito de obter uma perspectiva global dos dados coletados. Após, as interpretações das entrevistas foram construídas mediante o processo hermenêutico, que envolve um contínuo movimento entre as transcrições individuais e as compreensões que emergem do conjunto de dados (THOMPSON, 1997). A interpretação buscou descrever os padrões comuns de experiência entre os entrevistados. Da interpretação, surgiram os resultados que são detalhados e analisados na próxima seção. 


\section{Quadro 1. Perfis dos sujeitos entrevistados}

\begin{tabular}{|c|c|c|c|c|c|}
\hline \multicolumn{6}{|c|}{ Praticantes } \\
\hline Entrevistados & Idade (anos) & Profissão & Nível de Instrução & Bairro & Tipo de moradia \\
\hline $\mathrm{B}$ & 42 & Auxiliar de biblioteca & Médio & 4 & Casa \\
\hline C & 39 & Gerente de empresa & Superior & 3 & Apartamento \\
\hline E & 75 & Aposentada & Superior & 6 & Casa \\
\hline $\mathrm{F}$ & 31 & Dentista & Superior & 1 & Apartamento \\
\hline G & 41 & Jornalista & Superior & 5 & Cobertura \\
\hline $\mathrm{H}$ & 68 & Aposentada & Fundamental & 7 & Casa \\
\hline $\mathrm{K}$ & 66 & Aposentado & Fundamental & 9 & Casa \\
\hline $\mathrm{L}$ & 49 & Cabeleireira & Médio & 7 & Casa \\
\hline \multicolumn{6}{|c|}{ Especialistas } \\
\hline 1 & 41 & Agrônoma e empresária & Mestrado & Outro município & Casa \\
\hline 2 & 43 & Agrônomo e empresário & Mestrado & Outro município & Casa \\
\hline
\end{tabular}

\section{ANÁLISE DOS RESULTADOS}

Para auxiliar na interpretação e desenvolvimento dos achados da pesquisa, uma figura do esquema interpretativo dos resultados foi elaborada (Figura 1). Por meio da ilustração, é possível observar as principais relações teóricas que suportam o argumento da investigação: a AU é uma forma de consumo simbólico que questiona a lógica contemporânea de mercado, remetendo a relações nostálgicas de consumo e produção como resgate da herança cultural; proporciona uma sensação de bem-estar intrínseco, de flow e de prazer, servindo de exemplo social, uma espécie de ponte viva para as tradições do passado.

\section{Figura 1. Esquema interpretativo dos resultados}

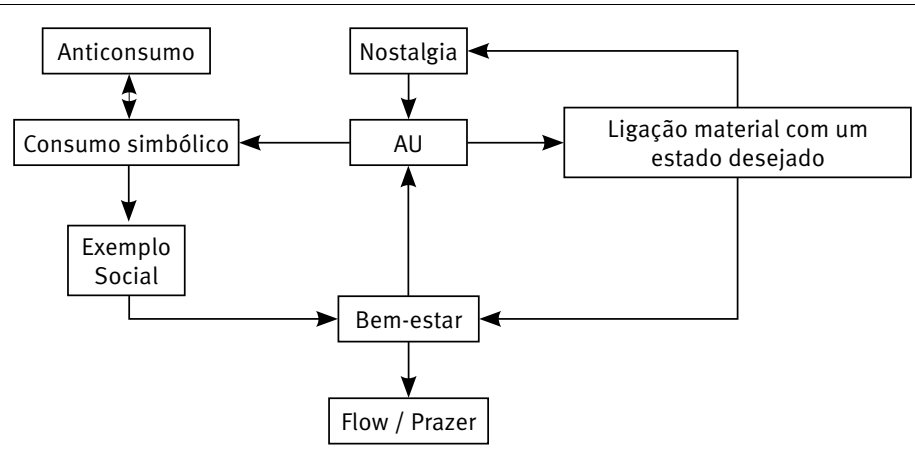

0 argumento de pesquisa apresentado anteriormente remete a conceitos trabalhados na Figura 1. A nostalgia motiva a prática da AU, que é uma ligação material com a tradição do passado e com a sensação de bem-estar geradora de flow e prazer. Ao mesmo tempo, a AU é uma forma de consumo simbólico, servindo como resgate cultural e exemplo social que traz orgulho para seus praticantes, o que também conduz ao bem-estar extrínseco enquanto questiona a lógica dominante do mercado. A seguir, são desenvolvidas as relações desses elementos. 


\section{Anticonsumo simbólico}

A relação anticonsumo-consumo é a base em que se apoia esta investigação. 0 questionamento quanto ao bem-estar associado à ideia de consumo é uma das explicações para essa constatação (DIAMANTOPOULOS e outros, 2003). Outro paralelo pode ser estabelecido com a pesquisa de Sassatelli e Davolio (2010) sobre a organização do Slow Food, cujas metas incluem defender a comida tradicional, assim como os métodos de cultivo de conservação, um panorama similar àquele apresentado nas entrevistas sobre AU.

Entretanto, os moldes do anticonsumo-consumo achados neste contexto não se referem à dimensão funcional do consumo, não estando relacionado diretamente a questões econômicas ou puramente racionais. 0 componente afetivo e experiencial da AU aproxima o fenômeno do tipo de anticonsumo-consumo chamado por Kozinets (2010) de expressivo. Semelhantemente, o trabalho de Hogg, Banister e Stenphenson (2009) sobre anticonsumo-consumo simbólico o define como um signo que serve ao propósito de identificação com os pares e rejeição aos diferentes; nesse caso, aqueles identificados com um estilo de vida consumista. Essa simbologia do anticonsumo-consumo, expressão social de orgulho por se considerar mais consciente como cidadão está impregnada na prática da AU, de conteúdo valorativo mais simbólico do que funcional. Isso pode ser percebido pela resposta do entrevistado A, praticante de AU há 30 anos. Quando questionado sobre o consumo das plantas que cultiva, afirmou que: "É maravilhoso, boto na mesa e faço a maior propaganda, olha isso, é do pátio. Temos um pé de limão, também a limonada é do pátio. A banana é do pátio. Adoro, acho o máximo".

Também o valor simbólico da atividade pode ser capturado pelo relato do entrevistado $\mathrm{C}$ ao expressar seu sentimento de orguIho pelo consumo dos produtos que planta no seu apartamento:

No Natal, em minha família cada um sempre leva um prato, faz anos que eu levo tabule, porque na primeira vez que eu levei a minha família gostou. E a hortelã é uma das que eu cultivo muito por causa disso. Esse ano, toda a hortelã que eu usei no tabule era daquele canteirinho, eu fiquei superorgulhosa (Entrevistado C).

Conforme os processos de significação/comunicação e de classificação/diferenciação social expostos por Baudrillard (2008) a respeito do consumo, constatou-se que, na $A U$, o consumo simbólico se refere ao ato de utilizá-lo como uma maneira de se comunicar, de transmitir uma mensagem às pessoas. Nas entrevistas com os praticantes de AU, percebeu-se que, por meio dessa atividade, há uma expressão da preocupação deles com o meio ambiente, a saúde e o bem-estar pessoal e dos demais. Alguns afirmaram que ficariam doentes, aborrecidos e frustrados se não pudessem mais lidar com as plantas. Constata-se a expressão de palavras que representam satisfação e bem-estar como sinais de quem a pessoa é e com o que se identifica (WATTANASUWAN, 2005; ELLIOTT, 1997): “Eu me realizo plantando porque eu gosto. Também pelo meio ambiente e saúde, principalmente pelos agrotóxicos” (Entrevistado E).

O processo de consumo pode ser utilizado para lograr certo status, classificação, imagem ou posição social (algo que também é apresentado nos estudos de Levy, 1959 e de Yoo, Chung e Han, 2006). Entre os entrevistados, observou-se que a prática de AU simboliza um ato de responsabilidade social e consciência, uma vez que, por meio dela, as pessoas tentam alcançar uma imagem de prestígio como cidadão exemplar e comprometido com a comunidade. Analogamente, outro elemento a ser ressaltado é a maneira como os entrevistados concebem o ato de cultivar a terra. Percebem como uma forma de valorizar e dignificar as pessoas que adotam a prática, imaginando que, por meio dela, se transformam em indivíduos mais virtuosos, conseguindo corrigir certos aspectos de suas vidas, porque "se de cada dez famílias, duas fizessem o que eu faço seria a salvação da humanidade" (Entrevistado J), ou como afirma outro praticante:

A gente tinha que ser mais assim natural. Também porque eu acho que é importante ter as árvores frutíferas, que as pessoas se conscientizem, ter uma cidade com bastante árvores frutíferas ao alcance do pedestre, ao alcance de todos. [...] Eu penso assim que a gente tem tanta terra e que tem que ter as árvores para poder alimentar o povo. Talvez eu plante porque tenho a esperança que alguém vai usar minhas árvores para se alimentar (Entrevistado B).

Nesse contexto, configura-se a existência de um significado simbólico de prestígio e exemplo para os demais, indo além do caráter funcional do consumo e representando outros sentimentos de identidade e comunicação pessoal, conforme destacado por Levy (1959) e Piacentini e Mailer (2004). Por exemplo, segundo o entrevistado I: "Quem pratica a atividade é um sábio, é um professor. Alguma coisa ele tem para ensinar" (Entrevistado I). Já o entrevistado A, ao ser questionado sobre o que pensa das outras pessoas que praticam a $\mathrm{AU}$, disse que:

Faz parte de um conjunto de coisas que faz com que a pessoa seja assim [uma boa pessoa], e que também transformam uma pessoa. Eu acho que é uma coisa muito interessante. Muita gente que está por aí, talvez indo para o caminho errado, se envolve com aquilo e aí acer- 
ta o passo. Além disso, passa a viver melhor, passa a ter uma boa alimentação (Entrevistado A).

Enfim, ao desenvolver a AU, constatou-se que as pessoas estabelecem uma forte relação com os aspectos sociais e de resgate de tradições familiares, comprometimento com as questões ambientais, de qualidade de vida, de lazer, hobby ou terapia. No entanto, não houve manifestações de influência da atividade nas questões econômicas do lar. Aspectos ratificados pelos dois especialistas entrevistados. Acredita-se que a afirmação, mencionada a seguir, sintetiza com clareza o sentido simbólico do consumidor/praticante de $\mathrm{AU}$, semelhante aos resultados encontrados por Jyrinki (2012) em seu estudo com animais de estimação, em que os sujeitos procuram uma fonte de bem-estar, meios de contato e comunicação de status, inseridos no contexto das interações sociais: "O mais legal é que eu consigo sentir o gosto da terra naquilo que eu planto e depois consumo. 0 gosto da terra é que dá o prazer. [...] Também tem relação com a perpetuação, de sentir-se dentro do ambiente" (Entrevistado I).

Por meio dessas manifestações percebe-se a busca dos entrevistados pela construção e transmissão de sua identidade coletiva, intimamente relacionada ao sentimento de orgulho e pertencimento social perante seus familiares e amigos a partir da experiência da AU e o resgate da tradição cultural representado pela nostalgia (PIACENTINI e MAILER, 2004; JYRINKI, 2012).

\section{Nostalgia}

A nostalgia mostrou-se como principal componente motivador direto para a prática da AU. Diversas entrevistas revelaram a ideia de resgate do passado, um reencontro emocional com um tempo vivido, com as raízes familiares, como demonstra este trecho: "O que eu tenho de lembrança de plantar que talvez seja uma coisa mais emocional é que eu morava num apartamento térreo quando era criança, e tinha um canteiro, e meu pai que usava aquele canteiro, botava pimenta, roseira, tinha um abacateiro" (Entrevistado C).

Essa passagem e outras - como a do Entrevistado J e sua lembrança do avô materno, a do Entrevistado I e o pai agricultor ou a do Entrevistado G e a mãe - estão alinhadas ao conceito de nostalgia quanto à preferência por objetos (práticas) que eram comuns quando se era mais jovem (HOLBROOK e SCHINDLER, 2003). Essas referências de memória afetiva também se aproximam da nostalgia como símbolo referente a pessoas amadas e à questão do lar, duas dimensões encontradas por Schindler e Holbrook (2003).

$\mathrm{Na}$ escolha de objetos representativos da prática de $\mathrm{AU}$, foi marcante a tendência nostálgica da tradição familiar. 0 entrevistado I, por exemplo, referiu-se a objetos antigos vincula- dos à agricultura (ferramentas) que pertenceram a pessoas da família e que estavam pendurados na área aberta do apartamento. Os objetos foram uma enxada e um chapéu de palha confeccionado pela avó. Suas escolhas justificaram-se pela forte relação com a família, a tradição, a terra, as origens e as questões históricas. Sendo assim, a nostalgia, como resgate das origens culturais, explica o interesse pela AU. 0 especialista 1 explicita isso ao relacionar a prática à colonização germânica e italiana do estado em que este estudo foi realizado que, para ele, foi determinante, pois os imigrantes trouxeram consigo o hábito de cultivar a terra.

Também é possível analisar a nostalgia em relação à AU da mesma forma que Lyon e Colquhoun (1999) ao estudar a utilização de imagens antigas nas marcas de alimentos. De certa forma, esse cultivo realizado no meio de uma cidade com quase 1,5 milhão de habitantes, que não preenche as necessidades de consumo e que não tem motivações financeiras, parece ser uma maneira de conexão com um passado percebido como sólido, produtivo e significativo. Por essa perspectiva, a nostalgia da AU pode ser uma maneira de lidar com a velocidade da atualidade, um fenômeno que desloca o tempo acelerado e instável do cotidiano para uma atividade contínua, que traz segurança e noção de tempo cíclico da natureza, resolvendo uma contradição contemporânea (LYON e COLQUHOUN, 1999). As palavras do Entrevistado D ilustram este ponto:

As plantas nos ensinam muito sobre essa questão de finitude, porque às vezes tem uma plantinha que eu estou curtindo, mas ela é uma planta anual, ela vive durante um ano depois ela morre. [...] Acho que isso é um aprendizado pra vida da gente também, pra gente saber que todos nós temos um ciclo (Entrevistado D).

Percebe-se que a nostalgia é determinante na motivação de iniciar a prática da AU sem ter uma relação direta com seu desenvolvimento, que se sustenta por outras razões, como saúde, entretenimento, contato com a natureza, escapismo e, principalmente, busca pelo bem-estar.

\section{Bem-estar}

Verifica-se nas entrevistas que a AU frequentemente está associada ao bem-estar. Ilustram essa afirmação declarações como: "Eu acho que torna a vida das pessoas mais interessante, mais alegre, mais feliz. Isso [a AU] agrega qualidade de vida" (Entrevistado D), ou "Planto pela minha cultura, alimentação e bem -estar" (Entrevistado B).

Observa-se também que, em muitos aspectos, a AU parece preencher as características estabelecidas na literatura para 
considerá-la uma atividade que contribui com a qualidade de vida de seus praticantes seja ela por ser prazerosa, trazer emoções positivas, proporcionar momentos relaxantes e de esquecimento dos problemas cotidianos ou incentivar a convivência com indivíduos que também valorizam a natureza.

A AU é uma atividade intencional, requer dedicação, é resultado de escolha individual e, em vários casos, reflete valores de seus praticantes. Sendo assim, contribui positivamente para o bem-estar (OISHI e outros, 1999). Nota-se que os sujeitos valorizam, em geral, o contato com a natureza e a alimentação saudável ou natural, valores alinhados à AU, pois praticam o que acreditam (Entrevistado G), são mais naturais (Entrevistados B e E) e se aproximam da natureza (Entrevistados D e A).

Em alguns casos, essa prática possui motivação intrínseca, pois é realizada sem preocupação com os resultados. Simplesmente pela sensação de autonomia (quem planta, planeja e realiza a atividade por si só), pertencimento (faz com que o sujeito seja bem visto pelos outros e possibilita o ingresso em círculos sociais) e competência (o agricultor é responsável pelo crescimento, beleza e sabor superior de suas plantas, o que o faz se sentir eficaz). Assim, da atividade emanam sentimentos de orgulho, como o entrevistado I que diz ser admirado pela vizinhança, retribuindo com pés de alface.

Segundo Rozin (1999, p. 113), o prazer é “um estado positivo experimentado que nós buscamos e tentamos manter e aumentar”. Existem três tipos de prazer, o sensorial ou físico (como aquele sentido quando se experimenta uma comida saborosa), o estético (prazeres abstratos, como o causado por uma boa música) e o de realização (derivados do alcance de alguma coisa que se valorize) (ROZIN, 1999). A AU é percebida como uma prática prazerosa em vários sentidos. 0 cheiro das flores e frutas, o contato com a terra e o sabor do alimento fresco são prazeres sensoriais relacionados à prática. Alguns sujeitos percebem prazeres estéticos, como o embelezamento de seus ambientes e a presença de pássaros e insetos, como borboletas. Existe, ainda, o prazer de ter seu empenho e cuidado recompensados com o crescimento de lindas plantas, o surgimento de flores e saborosos alimentos.

Essas sensações ficam claras em manifestações como: "São momentos prazerosos, eu gosto de ver as plantinhas crescendo" (Entrevistado C); ou "Têm jasmins. Quando estão floridos tem um cheiro muito gostoso. Eu gosto dos cheiros também” (Entrevistado D); ou ainda: "Dá uma alegria na gente ver a natureza, essas florzinhas” (Entrevistado B); “De vez em quando eu pego um tempero que eu planto e coloco na comida. Pra mim isso é uma alegria, de fazer isso, ter esse prazer” (Entrevistado F); “É uma coisa que me traz muita satisfação pessoal, de mexer com planta, de vê-las crescer, ver dar flor, botar a mão na terra" (En- trevistado D); e, finalmente, "Essa atividade me dá muito prazer e me faz relaxar do dia a dia, do trabalho" (Entrevistado G).

Além disso, essa prática torna disponível aos praticantes alimentos naturais, frescos e orgânicos que, segundo um entrevistado, além de serem mais benéficos, estimulam a manutenção de um hábito alimentar saudável. Assim, os agricultores urbanos entrevistados percebem uma influência positiva dessa prática em sua qualidade de vida, pois se trata de uma atividade prazerosa, alinhada a suas preocupações com saúde e meio ambiente. Acrescenta-se a isso o fato de que faz com que se sintam capazes e orgulhosos de seu trabalho e autônomos em sua realização, combatendo o estresse do dia a dia - uma forma de se desligarem das preocupações cotidianas.

\section{Flow}

Os entrevistados reportaram que a prática da AU se caracteriza como uma atividade na qual eles se envolvem completamente. Dessa forma, características relativas à experiência de flow foram observadas nas manifestações dos sujeitos. A atividade possibilita que os envolvidos fiquem imersos no processo que estão realizando e se sintam recompensados por isso, resultando numa sensação de bem-estar.

Para Csikszentmihalyi (1997a), a experiência de flow ocorre em atividades que exigem um esforço do praticante, com menor incidência em atividades passivas. Tal situação está presente na prática da $\mathrm{AU}$, conforme explicitado pelo Entrevistado D: “É uma atividade que me dá trabalho, mas não me incomodo com isso, não é algo chato".

A partir dessa afirmação, entende-se que a AU se configura como uma atividade propícia ao aparecimento da experiência de flow, pois envolve um esforço inicial do praticante, uma ação contínua, que culmina na sensação de felicidade. Além disso, há um equilíbrio entre os desafios da prática e as habilidades dos envolvidos, uma vez que o próprio indivíduo define o que irá plantar e o grau de dificuldade que enfrentará.

Um aspecto bastante explicitado durante as entrevistas foi a questão da distorção da percepção temporal. Isso pode ser exemplificado por passagens como: "Consigo me desligar completamente de tudo quando estou trabalhando na horta" (Entrevistado J) ou "Se eu dedico mais tempo a essa atividade, eu consigo ter foco e me desligar do mundo lá fora" (Entrevistado D). Assim, fica clara a imersão dos indivíduos na atividade, fazendo com que influências externas sejam ignoradas e que haja uma distorção do tempo decorrido durante o processo. Isso é resultado da intensa concentração no presente, que acaba por abrandar possíveis sensações de depressão e ansiedade da vida das pessoas (CSIKSZENTMIHALYI, 1997a). Esse comportamento de foco 
intenso exclui potenciais distrações da consciência (JACKSON, 2004). O relato do Entrevistado L corrobora com as ideias citadas anteriormente: “Quando vou para o jardim, passo o dia inteiro em função das plantas. Tenho que cuidar o horário, senão esqueço até mesmo do almoço. Quando vejo, já passou o dia”.

Ainda se verificou nas entrevistas que os objetivos dos praticantes não se relacionam a questões econômicas, o que contribui para que não exista uma preocupação com falhas, outra característica da experiência de flow. Os resultados obtidos com a atividade possuem importância secundária, ressaltandose, com maior relevância, o processo envolvido na sua execução. Na AU, o essencial são as etapas que compõem o processo pelo qual o indivíduo percorrerá no seu desempenho e não apenas o resultado final. Quanto mais o indivíduo estiver focado, vivenciando a experiência de flow, melhor será sua performance na tarefa que estiver desempenhando (JACKSON e CSIKSZENTMIHALYI, 2005C). Como consequência, maior será a sensação de prazer e bem-estar que poderá experimentar. A ligação entre a experiência de flow e a felicidade depende se a atividade que produz o flow é complexa - levar a novos desafios e, também, ao crescimento cultural e pessoal (CSIKSZENTMIHALYI, 1997b).

\section{CONSIDERAÇÕES FINAIS}

A prática da AU mostrou-se um contexto fértil para ampliar o conhecimento teórico sobre anticonsumo-consumo, especialmente quanto à agricultura urbana e ao consumo simbólico. Essa prática está relacionada a uma carga simbólica emocional que ativa um resgate da simplicidade do passado, ao mesmo tempo em que questiona as relações de excesso de consumo presentes. Dessa forma, o estudo do anticonsumo-consumo simbólico parece ser promissor, necessitando de ampliação para outros contextos, bem como diálogos com teorias psicológicas, antropológicas e sociológicas.

A motivação para praticar a AU está relacionada a duas dimensões, uma extrínseca e outra intrínseca. Por se tratar de uma forma de consumo simbólico, a AU serve como exemplo social, proporcionando orgulho para seus praticantes, o que traz bem-estar extrínseco, um contraponto à lógica dominante do mercado. Por outro lado, a AU também apresenta uma capacidade de gerar prazer, trazer emoções positivas, proporcionar momentos relaxantes e de esquecimento dos problemas cotidianos ou incentivar a convivência com indivíduos que também valorizam a natureza. Nesse caso, as motivações para a prática da AU são intrínsecas, sendo uma atividade realizada sem preocupação com os resultados, simplesmente pela sensação de autonomia, pertencimento e competência que dela emana.
A inexistência de influência da atividade nas questões econômicas do lar fortalece o entendimento de que a $\mathrm{AU}$ se relaciona com aspectos sociais, como o resgate de tradições familiares, o comprometimento com questões ambientais, a qualidade de vida, terapia ou lazer. Além disso, a nostalgia é um importante motivador para o início da prática de $A U$, contudo sem uma relação direta com seu desenvolvimento, sendo ela sustentada, essencialmente, pela busca do bem-estar.

Também contribui para a questão do bem-estar, que emerge da atividade de $\mathrm{AU}$, o fato de que suas características são similares às de outras atividades que proporcionam a experiência de flow. Dessa forma, a prática da AU é potencial para o aparecimento do estado mental de flow, que contribui para o bem-estar de seus praticantes.

Nesta pesquisa, o bem-estar proporcionado pela AU também está relacionado ao resgate das tradições e da simplicidade perdida, indo ao encontro de estudos que apontam que pessoas que têm plantas e animais em casa adoecem menos e vivem mais (HEADY, 1999). Nesta linha de pesquisa, dedicada a estudar formas de consumo que desafiem a lógica dominante do mercado, encontrar outros contextos nos quais essa prática esteja alinhada à noção de bem-estar, estendendo as possibilidades da busca pela realização pessoal, também se mostra importante.

Esta investigação apresenta como limitações o fato de a coleta de dados ter sido realizada apenas com 14 pessoas de uma única cidade e por não trazer evidências sobre a representatividade da atividade em estudo. Porém, tais aspectos, dessa forma limitadores, também podem ser considerados fatores positivos do trabalho, já que expõem subsídios para a realização de pesquisas de caráter quantitativo que incluam um universo mais amplo de pessoas e cidades com o intuito de comparar resultados.

Este estudo demonstra que a prática da AU se relaciona com a construção de uma identidade e a transmissão de uma imagem à sociedade. Percebe-se que seus praticantes a realizam não por sua característica utilitária (consumo de alimentos), mas principalmente por sua característica simbólica. Por meio dessa prática, as pessoas expressam e transmitem aos outros uma imagem de exemplo como membros da sociedade, agregando-lhes uma imagem de cidadãos preocupados com a coletividade. Ao mesmo tempo em que parecem idealizar a imagem do agricultor como uma pessoa nobre que, mediante o contato com a natureza e a prática de uma atividade simples como a agricultura, consegue resgatar valores perdidos na sociedade atual e vincula a prática à preocupação com o meio ambiente, com a saúde e o bem-estar próprio e dos demais, além de ter respeito e orgulho nostálgico por uma herança cultural. 


\section{REFERÊNCIAS}

BAUDRILLARD, J. A sociedade de consumo. Lisboa: Edições 70, 2008

BELK, R. W. Possessions and the extended self. Journal of Consumer Research, v. 15, n. 2, p. 139-168, 1998.

BISWAS-DIENER, R; DIENER, E. The subjective well-being of the homeless, and lessons for happiness. Social Indicators Research, v. 76, n. 2, p. 185-205, 2006.

CSIKSZENTMIHALYI, M. Finding flow. Psychology Today, v. 30, n. 4, p. 46-71, 1997 a.

CSIKSZENTMIHALYI, M. Happiness and creativity: going with the flow. Futurist. v. 31, n. 5, p. 8-12, 1997b.

DECI, E; RYAN, R. The "what" and "why" of goal pursuits: human needs and the self-determination of behavior. Psychological inquiry, v. 11, n. 4, p. 227-268, 2000.

DESPOMMIER, D. The rise of vertical farms: growing crops in city skyscrapers would use less water and fossil fuel than outdoor farm, eliminate agricultural runoff and provide fresh food. Scientific American, p. 32-39, 2009.

DIAMANTOPOULOS, A. e outros. Can socio-demographics still play a role in profiling green consumers? A review of the evidence and an empirical investigation. Journal of Business Research, v. 56, n. 6, p. 465-480, 2003.

DIENER, E. e outros. Subjective well-being: three decades of progress. Psychological Bulletin, v. 125, n. 2, p. 276-302, 1999.

DIENER, E; SELIGMAN, M. Beyond money: toward an economy of well-being. Psychological Science in the Public Interest, v. 5, n. 1, p. 01-31, 2004.

ELLIOTT, R. Existential consumption and irrational desire. European Journal of Marketing, v. 31, n. 3/4, p. 285-296, 1997.

ETTEMA, D. e outros. Out-of-home activities, daily travel and subjective well-being. Transportation Research, v. 44, n. 9, p. 723-732, 2010.

GABRIEL, Y; LANG, T. New faces and new masks of today's consumer. Journal of Consumer Culture, v. 8, n. 3, p. 321-340, 2008.

GOULDING, C. Romancing the past: heritage visiting and the nostalgic consumer. Psychology \& Marketing, v. 18, n. 6, p. 565-592, 2001.

GOULDING, C. Grounded theory, ethnography and phenomenology: a comparative analysis of three qualitative strategies for marketing research. European Journal of Marketing, v. 39, n. 3/4, p. 294-308, 2005.

HEADY, B. Health benefits and health cost savings due to pets: preliminary estimates from an australian national survey. Social Indicators Research, v. 47, n. 2, p. 233-243, 1999.

HOGG, M. K; BANISTER, E. N; STENPHENSON, C. A. Mapping symbolic (anti-) consumption. Journal of Businness Research, v. 62, n. 2, p. 148159, 2009.

Holbrook, M. B. Nostalgia and consumption preferences: some emerging patterns of consumer tastes. Journal of Consumer Research, v. 20, n. 2, p. 245-256, 1993.

HOLBROOK, M. B; Schindler, R. M. Nostalgic bonding: exploring the role of nostalgia in the consumption experience. Journal of Consumer Behaviour, v. 3, n. 2, p. 107-127, 2003.

INSTITUTO BRASILEIRO DE GEOGRAFIA E ESTATÍSTICA. Disponível em: 〈www.ibge.gov.br/home〉. Acesso em 27.03.2011.
JACKSON, B. H. Finding flow. Personal Excellence, v. 9, n. 9, p. 03-03, 2004 .

JACKSON, S; CSIKSZENTMIHALYI, M. Focus on the present. Personal Excellence, v. 10, n. 2, p. 8, 2005 a.

JACKSON, S; CSIKSZENTMIHALYI, M. Four keys to flow. Personal Excellence, v. 10, n. 3, p. 9, 2005 b.

JACKSON, S; CSIKSZENTMIHALYI, M. Keys to your game plan. Personal Excellence, v. 10, n. 6, p. 7, 2005 C.

JYRINKI, H. Pet-related consumption as a consumer identity constructor. International Journal of Consumer Studies, v. 36, n. 1, p. 114-120, 2012.

KLEIN, J. G; SMITH, C. N; JOHN, A. Why we boycott: consumer motivations for boycott participation. Journal of Marketing, v. 68, n. 3, p. 92109, 2004 .

KOZINETS, R. V. Don't read this; or, who cares what the hell anti-consumption is, anyways? Consumption Markets \& Culture. Vol. 13, n. 3, p. 225-233, 2010.

LEVY, S. Symbols for sale. Harvard Business Review, v. 37, n. 4, p. 117124, 1959.

LYON, P; Colquhoun, A. Selectively living in the past: nostalgia and lifestyle. Consumer Studies \& Home Economics, v. 23, n. 3, p. 191-196, 1999.

MCCLINTOCK, N. Why farm the city? Theorizing urban agriculture through a lens of metabolic rift. Cambrige Journal of Regions, Economy and Society, v. 3, n. 2, p. 191-207, 2010.

OBSERVATÓRIO DA CIDADE PESQUISADA. Disponível em: 〈www2.portoalegre.rs.gov.br/observatorio/default.php?p_secao=91>. Acesso em 27.03.2011.

OISHI, S. e outros. Value as a moderator in subjective well-being. Journal of Personality, v. 67, n. 1, p. 157-184, 1999.

PIACENTINI, M; MAILER, G. Symbolic consumption in teenagers' clothing choices. Journal of Consumer Behaviour, v. 3, n. 3, p. 251-262, 2004

ROZIN, P. Preadaptation and the puzzles and properties of pleasure. In: KAHNEMAN, D; DIENER, E; SCHWARZ, N. Well being: the foundations of hedonic psychology. New York: Russell Sage, p. 109-133, 1999.

SASSATELLI, R; DAVOLIO, F. Consumption, Pleasure and Politics Slow Food and the politico-aesthetic problematization of food. Journal of Consumer Culture, v. 10, n. 2, p. 202-232, 2010.

SCHINDLER, R. M; HOLBROOK, M. B. Nostalgia for Early Experience as a Determinant of Consumer Preferences. Psychology \& Marketing, v. 20, n. 4, p. 275-302, 2003.

SHAW, D; NEWHOLM, T; DIKINSON, R. Consumption as voting: an exploration of consumer empowerment. European Journal of Marketing, v. 40, n. 9/10, p. 1049-1067, 2006.

SLATER, R. Urban agriculture, gender empowerment: an alternative view. Development Southern Africa, v. 18, n. 5, p. 635-650, 2001.

SMIT, J; NASR, J. Urban agriculture for sustainable cities: using wastes and idle land and water bodies of resource. Environment and Urbanization, v. 4, n. 2, p. 141-152, 1992.

THOMPSON, C. J. Interpreting Consumers: a Hermeneutical Framework for Deriving Marketing Insights from the Texts of Consumers Consumption Stories. Journal of Marketing Research, v. 34, p. 438-455, 1997.

THOMPSON, C. J; COSKUNER-BALI, G. Enchanting Ethical Consumerism: the case of Community Supported Agriculture. Journal of Customer Culture, v. 7, n. 3, p. 275-303, 2007. 
THOMPSON, C. J; LOCANDER, W. B; POLLIO, H. R. Putting consumer experience back into consumer research: the philosophy and method of existential-phenomenology. Journal of Consumer Research, v. 16, n. 2, p. $133-147,1989$.

VEENHOVEN, R. Questions on happiness: classical topics, modern answers, blind spots. In: TRACK, F; ARGYLE, M; SCHWARZ, N. Subjective well-being, an interdisciplinary perspective. London: Pergamon Press, p. 07-26, 1991.
WATTANASUWAN, K. The Self and Symbolic Consumption. The Journal of American Academy of Business, Cambridge, v. 6, n. 1, p. 179$185,2005$.

YOO, S; CHUNG, S. H; HAN, J. K. A Durable Replacement Model for Symbolic versus Utilitarian Consumption: an integrated cultural and socio-economic perspective. Global Economic Review, v. 35, n. 2, p. 193206, 2006. 